\title{
Promoção e Educação em Saúde: Uma Análise Epistemológica
}

\author{
Health Promotion And Education: \\ An Epistemological Analysis \\ Promoción Y Educación En Salud: \\ Un Análisis Epistemológico
}

Inea Giovana Silva-Arioli, Daniela Ribeiro Schneider,

Tatiane Muniz Barbosa \& Marco Aurélio Da Ros

Universidade Federal de Santa Catarina
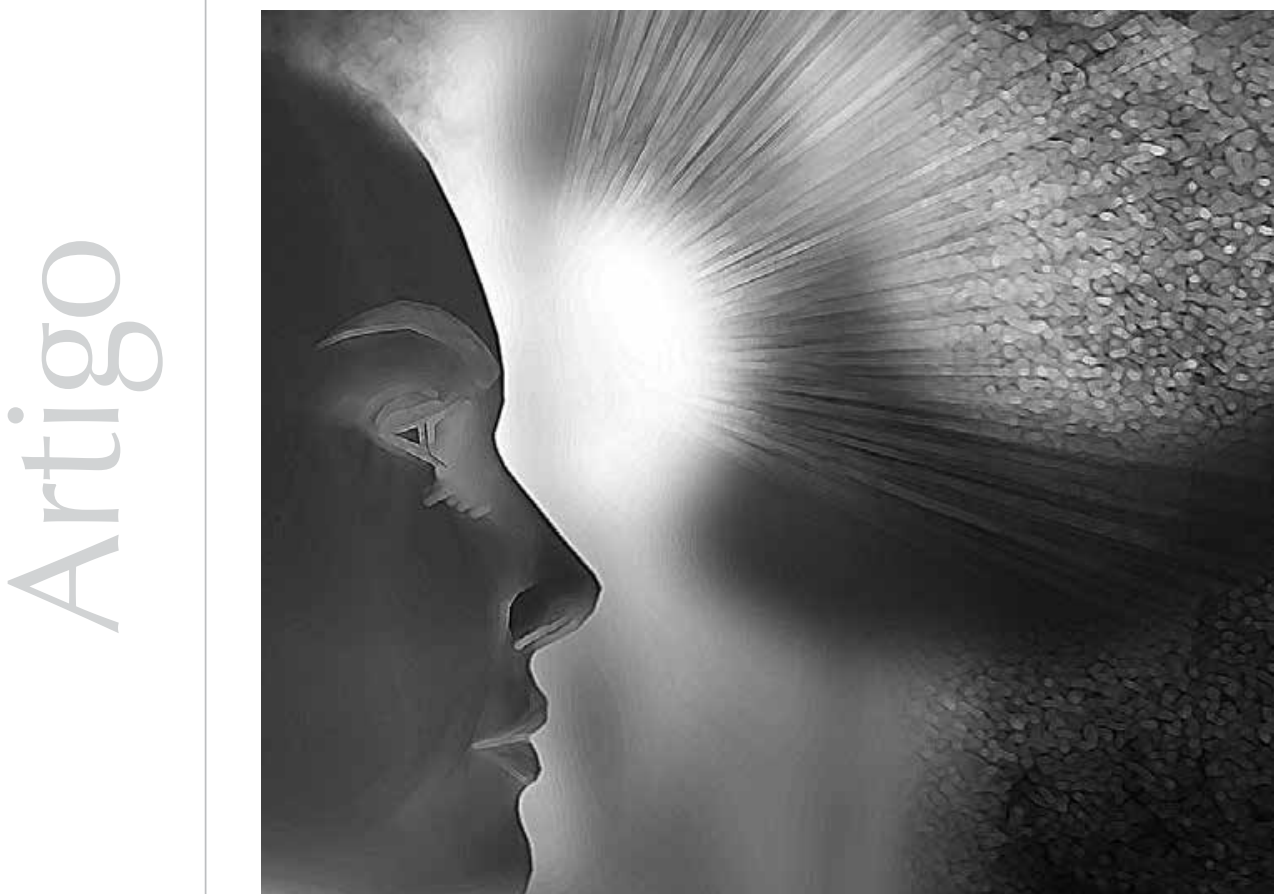
Resumo: Este artigo tem como objetivo contextualizar epistemologicamente os conceitos de promoção e de educação em saúde, buscando refletir sobre os estilos de pensamento que permeiam as concepções e as práticas nessa área. Para isso, busca-se delimitar as formas de perceber o campo da saúde, como construção coletiva de saberes e de práticas determinada historicamente dentro do contexto brasileiro, explicitando as macrotendências em saúde. Evidencia-se a articulação e o encadeamento de concepções, ideologias e a proposição de ações nos vários níveis do fazer saúde. Discute-se como as práticas hegemônicas influenciam nas dificuldades de efetivação dos princípios do Sistema Único de Saúde (SUS) no Brasil. Não se trata apenas de superar obstáculos da ordem do conhecimento, mas de construir concepções e práticas que estabeleçam uma nova relação com esses conhecimentos e que sejam mais coerentes com as premissas do SUS.

Palavras-chave: Promoção em saúde. Educação em saúde. Sistema Único de Saúde. Epistemologia.

Abstract: This article, through literature review, aims to contextualize the epistemological concepts of health promotion and education, trying to reflect on the styles that permeate the concepts and practices in this area. For this we seek to define the ways of perceiving the field of health, as a collective construction of knowledge and practices historically determined in the Brazilian context, explaining the macro-trends in health. This study highlights the articulation and linking of ideas and ideologies and proposes actions to the various levels of health. It discusses how the hegemonic practices influence the practical difficulties of the principles of the Unified Health System in Brazil. The intention is not just to overcome obstacles in knowledge, but to build concepts and practices that establish a new relationship with this knowledge and that are more consistent with the assumptions of the Unified Health System in Brazil.

Keywords: Health promotion. Health education. Unified Health System. Epistemology.

Resumen: Este artículo tiene como objetivo contextualizar epistemológicamente los conceptos de promoción y educación en salud, buscando reflexionar sobre los estilos de pensamiento que afectan las concepciones y prácticas en esta área. Para esto, se busca delimitar las formas de percibir el campo de la salud, como construcción colectiva de saberes y prácticas determinadas históricamente dentro del contexto brasileiro, explicitando las macro tendencias en salud. Se evidencia la articulación y encadenamiento de concepciones, ideologías y proposición de acciones en los varios niveles del hacer salud. Se discute cómo las prácticas hegemónicas influencian en las dificultades de efectivación de los principios del Sistema Único de Salud (SUS) en el Brasil. No se trata apenas de superar obstáculos del orden del conocimiento, sino de construir concepciones y prácticas que establezcan una nueva relación con estos conocimientos y que sean más coherentes con las premisas del SUS.

Palabras clave: Promoción en Salud. Educación en Salud. Sistema Único de Salud. Epistemología.

Pesquisar sobre qualquer área do conhecimento implica situar de que lugar se fala ou como se constrói a diversidade de conhecimentos sobre o referido processo, ou seja, implica indicar nosso estilo de pensamento. O termo estilo de pensamento provém da epistemologia construtivista de Ludwik Fleck (1935/2010), que concebe a ciência como algo que nunca é realizado individualmente, mas sempre cooperativamente entre pesquisadores. Dada a consideração da complexidade do fenômeno saúde/doença, Fleck afirma que não é possível uma visão global ou unitária, mas sim, diversos pontos de vista sobre esse fenômeno (Matos, Gonçalves, \& Ramos, 2005). Tais considerações levam à existência, tanto no campo disciplinar quanto no prático, de diferentes perspectivas ou formas de perceber uma dada realidade, embasadas em diferentes pressupostos, apesar de observarem os mesmos fenômenos ou fatos científicos.

Essas percepções são dirigidas, na medida em que são compartilhadas por um coletivo de pensamento, que constrói um corpo teórico estruturador e que corresponde a uma determinada prática, nesse caso, especificamente as práticas da área da saúde. Sendo assim, para Fleck, um estilo de pensamento não existe individualmente, mas na interioridade de determinado coletivo de pensamento que, para o autor, designa a unidade social da comunidade de cientistas, ou ainda, a unidade de um campo determinado do saber, ou seja, de um grupo profissional (Matos et al., 2005).

A partir desse olhar, o presente artigo pretende discutir os diferentes estilos de 
pensamentos existentes na área da saúde; o artigo aborda as consequências desses estilos especificamente em relação à promoção e à educação em saúde, situando esses temas no cenário da saúde brasileira e apontando as macrotendências envolvidas nesse processo.

No entanto, antes de enveredarmos por esse caminho, realizaremos uma pequena revisão sobre a categoria epistemologia: afinal, como se produz o conhecimento em geral? Com base nessas reflexões, partiremos, então, para pensar sobre a produção do conhecimento em saúde.

Japiassu (1992) afirma que ainda se sabe pouco sobre epistemologia e que as fronteiras na investigação dessa disciplina são muito dinâmicas, tendo em vista que ora se aproxima da Filosofia, ora se coloca como autônoma em relação a essa. O autor, pontua, dessa forma, que atualmente há uma variedade de conceitos de epistemologia, e isso pode dar-se porque, quando o discurso epistemológico surgiu, no século XIX, apresentava uma filiação dupla e ambígua quando assumia a ciência como seu objeto, ainda que encontrasse seus princípios na Filosofia.

Mas o avanço dos tempos e dos estudos indica que a epistemologia, como disciplina, deixa de ser lócus de pesquisa exclusivo da Filosofia e passa a ser obra também dos cientistas (Japiassu, 1992). Nesse caminho, a epistemologia se desenha de diferentes formas, considerando que o conhecimento é visto sob diferentes olhares (os diferentes estilos de pensamento dos cientistas/ pesquisadores). A própria abordagem sobre a epistemologia, por exemplo, varia conforme as condições históricas e as raízes filosóficas e sociais que a constroem. Sendo assim, os positivistas tendem a ver a ciência como um conhecimento em si, postulando-a de maneira acrítica, sem sua contextualização histórica, adotando uma perspectiva de objetividade pura e de neutralidade, e, com isso, uma perspectiva mais reducionista em seus estudos. Já para correntes como o construtivismo (de Vygotsky e Fleck), a epistemologia é o estudo crítico, histórico e temporal das diversas ciências, que constroem verdades relativas.

Sendo assim, é impossível estabelecermos um conceito único e preciso de epistemologia, isso porque a categoria depende de quem vai produzi-la, por que e como a fará, ou seja, a produção de conhecimento é interdependente das relações existentes entre as ciências e a sociedade, em suas diversas dimensões. Nessa acepção, o conhecimento é entendido como processo, produto e produtor de história, que nos permite captar, de modo relativo, a realidade a ser conhecida (Japiassu, 1992). Considerando esses entendimentos, a epistemologia caracteriza-se como o estudo reflexivo do saber, de sua organização, de sua formação, de seu desenvolvimento, de seu funcionamento e de seus produtos intelectuais. Mas deve implicar um processo flexível, no sentido dialético do pensamento e do saber. Episteme é, assim, para esse autor, o campo onde, em um tempo preciso, se determinam as condições de possibilidade do conhecimento e os princípios de sua ordenação. É importante ressaltar, no entanto, que "qualquer que seja a acepção que dermos ao termo 'epistemologia', a verdade é que ela não pode e nem pretende impor dogmas aos cientistas" (Japiassu, 1992, p. 38).

Consoante isso, considerar a área da saúde tem se colocado como um desafio que deve considerar a sociedade e suas mudanças em diversas dimensões, pois, segundo Delizoicov, Castilho, Cutolo, Da Ros e Lima (2002), os fatos científicos devem ser contextualizados, e à epistemologia cabe historizar e sociologizar o fato científico para compreender a transitoriedade das verdades científicas. "As verdades que se mostram estão impregnadas de um estilo de pensamento 
condicionado pela atividade histórico-social do ser humano" (Delizoicov et al., 2002, p. 58).

$\mathrm{Na}$ área da saúde, existem várias formas de conceber e de construir conhecimento, que embasam diferenciadas práticas. A ampliação das fronteiras do setor, com a adoção de um conceito de saúde pela Organização Mundial da Saúde (OMS), em 1947, envolve sua vinculação às condições de vida das populações e desencadeia uma renovação em toda a área da saúde. No contexto brasileiro, o movimento da reforma sanitária (a partir de 1970) promove a discussão crítica do modelo de assistência à saúde, lançando as bases para a construção e a viabilização do Sistema Único de Saúde (SUS). Esse movimento sustenta-se em novos estilos de pensamento em saúde que, de certa forma, se unificam ao se oporem à concepção hegemônica anterior, sustentada em estilos de pensamento clássicos em saúde, centrados nos pressupostos biomédicos. Apesar de fundamentais nas transformações do mundo contemporâneo, esses movimentos críticos não dão conta de superar o predomínio, ainda forte, da perspectiva biomédica.

Essas formas diferenciadas de fazer saúde são a expressão dos novos desafios sociopolíticos das últimas décadas, que descortinam o acirramento da disputa de projetos de sociedade e que abarcam as diversidades epistemológica, ideológica e prática. A disputa do poder na área da saúde acontece no cerne do avanço do neoliberalismo, protagonizada pela retração das políticas sociais universalistas e redistributivas, em que a saúde deixa de figurar como um bem comum e passa a ser encarada como uma mercadoria, portanto, regida pelas leis do mercado. Essa conjuntura socioeconômica leva à intensificação da distribuição desigual de bens e do acesso a serviços, ao aumento da pobreza, da violência e do desemprego, à precarização do trabalho e ao agravamento sem precedentes das desigualdades sociais. Tal situação contribui para o adoecimento da população e, em consequência, para o aumento por atenção em saúde. Esse cenário, aliado ao processo de retração estatal no que concerne às políticas sociais e que incluem cortes de direitos adquiridos, exime o Estado da responsabilidade que lhe cabe na construção de sociedades mais justas, o que implicaria aumento de subsídios para setores como a saúde (Carvalho, 2010; Lacerda \& Valla, 2007). Vale ressaltar que o Brasil, na contramão do aumento do neoliberalismo, é terreno fértil para o desenvolvimento de uma política estatal inclusiva, impulsionada pelo movimento da reforma sanitária e consolidada pelo SUS.

Tais considerações apontam, portanto, um cenário no qual estilos de pensamento opostos marcam presença e disputam o controle das práticas sanitárias, delimitando claramente duas macrotendências no campo da saúde brasileira: o modelo biomédico e o da saúde coletiva. O primeiro caracteriza-se por uma lógica que centra suas concepções nas causas biológicas para explicar os fenômenos da saúde/doença entendidos como aspectos dicotômicos entre si, pautando-se em práticas centradas na medicalização do sofrimento e no sistema de saúde centrado no modelo hospitalocêntrico (Coelho \& Almeida Filho, 2002). O segundo coloca-se como um campo de práticas e de conhecimentos caracterizado por um pensamento sobre a saúde que transcende a questão da doença em si mesma, postulando a multidimensionalidade do fenômeno, caracterizando sua ênfase na saúde coletiva, integralidade e determinação social do processo saúde/doença, concebida de forma hierarquizada, com ênfase na porta de entrada da atenção básica e com postulados de integralidade das ações em saúde: remediação, recuperação, prevenção, promoção.

Conforme as palavras de Coelho e Almeida Filho: 
Do ponto de vista das práticas e políticas de saúde, os sistemas de saúde do mundo ocidental, e, nele, do Brasil, têm sido questionados por sua dependência em relação a um modelo assistencial individualista, com ênfase na dimensão curativa da doença além dos elevados custos e da baixa efetividade. Ganha força, então, a idéia de promover a saúde, e não apenas de curar a doença, emergindo daí os conceitos de vigilância da saúde, políticas públicas saudáveis e cidades saudáveis, articulados à noção de promoção da saúde pela mudança das condições de vida e de trabalho da população (2002, p. 316)

\section{Pensando sobre a promoção de saúde}

A promoção da saúde abarca um corpo de conhecimentos dotado de conceitos profícuos e fortes, mas também traz em seu bojo ambiguidades, limitações e omissões, apresentando-se como um dinâmico campo em construção (Campos, 2010). A discussão de seus princípios tem contribuído para a renovação do discurso sanitário, pela contraposição ao modelo biomédico e pelo resgate da determinação social do processo saúde/doença, mas seu ideário está longe de ser uníssono. Ao inspirar-se em filosofias políticas diversas, manifesta imagens-objetivo diferentes e práticas opostas em muitos casos, que ampliam ou restringem as intervenções no campo da saúde (Rabello, 2006).

O moderno movimento de promoção da saúde surgiu no Canadá, em 1974, e vem sendo elaborado no cenário internacional por diferentes atores e discursos ao longo dos últimos 30 anos. O primeiro grande evento mundial desse movimento foi a $I$ Conferência Internacional sobre Promoção da Saúde (1986), na qual foi redigida a Carta de Ottawa, um dos documentos de referência nessa área. Inúmeros eventos internacionais, publicações e pesquisas têm contribuído para a discussão nesse âmbito, destacando- se: o Relatório Lalonde, (Canadá, 1974), a I Conferência Internacional sobre Cuidados Primários de Saúde (Alma-Ata, 1978), as seis Conferências Internacionais de Promoção da Saúde (Canadá, 1986; Austrália, 1988; Suécia, 1991; Jacarta, 1997; México, 2000; Bangcok, 2005) e o Epp Report (Canadá, 1986), entre outros (Buss, 2009).

O Relatório Lalonde aborda o campo saúde, introduz a análise dos chamados determinantes da saúde e propõe o planejamento estratégico na área, estabelecendo as bases para uma nova forma de avaliar a saúde, firmada quatro anos mais tarde em Alma-Ata. Esse relatório considera os aspectos da biologia humana, do ambiente, dos estilos de vida e da organização da atenção como princípios norteadores da intervenção em saúde. A I Conferência Internacional sobre Cuidados Primários de Saúde incorpora o debate sobre a determinação social do processo saúde/ doença e teve significativa importância na medida em que trouxe um novo enfoque para esse campo (Buss, 2009; Oliveira, 2008).

A Carta de Ottawa (Brasil, 2002), como marco desse movimento, afirma um conjunto de valores como saúde, democracia, solidariedade, equidade, participação e ação conjunta como resultado de diversas estratégias para a melhoria da qualidade de vida, discutidas na I Conferência Internacional sobre Promoção da Saúde. As conferências subsequentes apontam várias necessidades e prioridades, enfatizando a importância da articulação do setor saúde com os diversos setores sociais e reafirmando a determinação social do processo saúde/doença. Já o Epp Report (1986) mantém estreita relação com a Carta de Ottawa, mas avança em relação a ela ao indicar como estratégias o fortalecimento dos serviços comunitários e o favorecimento da participação popular, por meio do empowerment, como elementos-chave para alcançar saúde (Buss, 2009; Heidmann, Almeida, Boehs, Wosny, \& Monticelli, 2006). 
Como

pertinentemente lembra Heidmann (2006), a

promoção em saúde constitui um modo de dar significado à saúde e à doença, e, nesse sentido, pode trazer contribuições para o rompimento do modelo biomédico.
A Constituição Brasileira de 1988 apresenta um novo conceito de assistência à saúde e reconfigura direitos, deveres e desafios da sociedade. Além de utilizar um conceito ampliado de saúde, em que esta é entendida como bem coletivo diretamente ligado às condições concretas de vida das pessoas, inova ao priorizar a promoção de saúde e ao introduzir a participação social no controle das ações nessa área (Gallo \& Espírito Santo, 2009). Nesse sentido, um dos desafios da promoção em saúde reside em transformar um sistema que tradicionalmente se sustenta na doença em um propulsor de ações que priorizem a vida e a saúde em seu significado mais amplo, pautado em relações horizontais e em parâmetros de corresponsabilização.

Sendo assim, baseados na Carta de Ottawa, os documentos oficiais da política de saúde no Brasil evidenciam a promoção de saúde como: "o processo de capacitação da comunidade para atuar na melhoria da sua qualidade de vida e saúde, incluindo maior participação no controle desse processo" (Brasil, 2002, p. 19).

No entanto, esse conceito esconde várias tensões teóricas e filosóficas, que correspondem a práticas muitas vezes contraditórias. Apesar de a promoção em saúde estar diretamente vinculada à autonomia dos sujeitos, na prática, a população dificilmente aparece como protagonista nos cuidados com sua saúde, situação sustentada por um histórico de relações verticais não somente no cotidiano das unidades de saúde e de outros níveis de atenção mas também nas definições macropolíticas, que muitas vezes relegam ao usuário o papel de passividade.

Como pertinentemente lembra Heidmann (2006), a promoção em saúde constitui um modo de dar significado à saúde e à doença, e, nesse sentido, pode trazer contribuições para o rompimento do modelo biomédico. Por outro lado, a forma de promover saúde pode reforçar o modelo clássico de fazer saúde, que implica uma significação radicalmente diferente para as ações nesse âmbito. Dito de outro modo, os direcionamentos das ações que promovem saúde dependem da perspectiva epistemológica da saúde em que se está embasado. Dentro desse contexto, vários autores, como Castiel e Diaz (2007), Czeresnia (2009), Verdi e Caponi (2005) e Carvalho (2004), entre outros, apontam a existência da mesma dicotomia do campo da saúde em geral, indicando duas macrotendências no que concerne ao conceito/estratégia da promoção em saúde, dois polos que se opõem e se mostram incomensuráveis entre si, característica típica de dois estilos de pensamento, isso porque o que se descortina é o acirramento da disputa de projetos de sociedade, que abarcam diversidade epistemológica, ideológica e prática, alimentando a pluralidade de reflexões.

Em um dos polos, encontra-se a promoção de saúde calcada na busca pela modificação dos estilos de vida, que marca o projeto da Promoção de Saúde Behaviorista (PSB) ou comportamental, e que parte do pressuposto que as atitudes e os comportamentos inadequados são os responsáveis por uma considerável parcela dos problemas de saúde da população. Essa abordagem procura romper o modelo biomédico ao focalizar a atenção na melhoria do ambiente (alterando o foco das ações sanitárias) e na redução de riscos autoimpostos, sendo apontada como a perspectiva dominante nas práticas de promoção da saúde (Carvalho, 2010; Heidmann, 2006; Rabello, 2006). Tal perspectiva ainda está atrelada a um modelo preventivista, pois a saúde é percebida em oposição à doença, e a doença é vinculada à falta de cuidados (Luz, 2007).

Em alguns países, como nos Estados Unidos, existem sites especializados que oferecem 
conselhos de saúde personalizados, entre outros recursos, objetivando a mudança para estilos de vida mais saudáveis. Esses sites são recomendados por profissionais da área da saúde, prioritariamente médicos, como coadjuvantes na transformação do comportamento, com vista à melhoria das condições de saúde da população (Woolf et al., 2006).

Carvalho (2010) afirma que estudos comprovam a melhoria significativa da qualidade de vida de alguns grupos sociais no Canadá, derivada da utilização dessa estratégia. Mas o mesmo autor ainda ressalta que esse resultado positivo está diretamente vinculado à posição social que o indivíduo pertence, ou seja, as populações melhor situadas na escala social têm melhoria das condições de saúde, sendo que as populações mais carentes sofrem um agravamento dessas condições. Segundo Figueira, Ferreira, Schall e Modena (2009), em ambientes desfavoráveis, a responsabilização do sujeito e a culpa pela não adoção do estilo de vida preconizado levam a um sentimento de incapacidade e de diminuição da autoestima. Essa desvalorização geralmente produz passividade diante das situações, alimentando a incapacidade de mudança.

Na PSB, é delegada à população a responsabilidade pela melhoria de suas condições de saúde, o que favorece o processo de culpabilização da vítima, ao diluir o social em uma retórica comportamental ahistórica, considerando como fator determinante do cuidado a força de vontade individual (Carvalho, 2010; Castiel \& Diaz, 2007; Fernandez, Andrade, Pelicioni, \& Pereira 2008; Figueira et al., 2009; Rabello, 2006). Deixa-se de levar em consideração que, em alguns ambientes, determinados comportamentos não saudáveis são inevitáveis, e que alguns estilos de vida são inacessíveis às populações. Essa ênfase na modificação das atitudes e dos estilos de vida mascara a determinação social da saúde e centraliza as ações no aspecto individual, em detrimento de estratégias mais amplas de intervenção (Calatayud, 1999; Castiel, 2006).

Partindo da análise do conceito de autonomia, Czeresnia (2009) ressalta que, nessa perspectiva, a autonomia incentivada é regulada por certa lógica cultural, científica e de mercado, negando aos usuários a possibilidade de refletir acerca de suas condições de vida e de saúde na busca da superação de suas dificuldades não só de forma individual mas também coletivamente.

As estratégias educacionais, vinculadas a essa forma de perceber a promoção da saúde, destinam-se a informar as pessoas sobre o que é saudável, influenciando os hábitos e os comportamentos, e estão quase sempre calcadas em uma perspectiva pedagógica de relações verticais, em que o saber dos técnicos predomina sobre a autonomia dos sujeitos. Utiliza-se o conceito de empowerment psicológico, a partir do qual o indivíduo, munido de informações adequadas, pode fazer as escolhas saudáveis e ter a sensação do controle das situações (Castiel, 2006). No entanto, o sentimento de poder é radicalmente divergente da possibilidade de intervir nos condicionantes da saúde, que, em sua grande maioria, são controlados pela política e pelas práticas macrossociais, o que evidencia a tendência do empowerment psicológico de ignorar a influência dos fatores estruturais. Não se trata de negar a importância dessa forma de emancipação individual, mas de ressaltar que ela desconsidera o contexto político e histórico das pessoas envolvidas (Carvalho, 2010).

Ainda é pertinente ressaltar as questões éticas referentes a essa posição. Castiel e Diaz advertem para a existência de juízos de valor implícitos, a indução de uma vida marcada pela padronização e pela regularidade das 
atividades cotidianas, que conformam as identidades e não se referem apenas a como agir, mas que também delimitam quem ser. Nesse processo, a saúde passa a ser um fim em si mesmo às custas da autonomia dos indivíduos e das coletividades, e pode conduzir à discriminação dos não saudáveis, esvaziando-se dos aspectos políticos que permeiam o campo. Essa saúde promocional apresenta-se como portadora de concepções biopolíticas, que exercem a função de controle e de regulação da área social e que, portanto, mantêm o status quo (Gaudenzi \& Schramm, 2010; Sant'Anna \& Hennington, 2010).

No outro polo e em perspectiva oposta, encontra-se a macrotendência da nova promoção da saúde (NPS). Essa perspectiva partilha com a anterior a crítica ao modelo biomédico e a necessidade de ampliar o entendimento do processo saúde/doença, mas transcende-a ao apontar a relação negativa existente entre iniquidade social e saúde, evidenciando que a forma como a sociedade se organiza tem relação direta com as suas condições de saúde. A perspectiva em questão considera a saúde um direito e um bem comum, e prioriza como estratégias a constituição de políticas públicas saudáveis, a criação de ambientes sustentáveis, a reorientação dos serviços de saúde, o fortalecimento de ações comunitárias e o desenvolvimento da capacidade individual e comunitária (Carvalho, 2010). É necessário ressaltar que essa tendência apresenta ambiguidades e divergências internas relevantes, entre elas, a de encontrar estratégias efetivas de serem postas em prática. Aqui, no entanto, ressaltar-se-ão os pontos principais que a norteiam, como polo de compreensão do campo da promoção de saúde que se apresenta em contraposição a outro polo.

A NPS tem como pressuposto a compreensão ampliada do processo saúde/doença e de seus determinantes, propondo a articulação de conhecimentos científicos e populares para seu enfrentamento; busca, assim, "uma revalorização do social como fonte e explicação dos problemas de saúde e como recurso a ser mobilizado para enfrentá-los" (Buss, 2000, p.16). Essa tendência amplia o âmbito das ações em saúde ao realizar uma síntese inovadora dos conceitos originários de outros campos disciplinares, inserindo o debate sobre a necessidade da construção de uma consciência crítica sobre os problemas de saúde. A NPS reconhece a complexidade dos fatores micro e macrossociais, procurando pautar as práticas que buscam a transformação na reflexão crítica, na equidade e no fortalecimento comunitário (Rabello, 2006; Santos, Oliveira, Crepaldi, \& Da Ros, 2010).

É necessário realizar a diferenciação dos termos fortalecimento e empowerment, pois podem, à primeira vista, parecer sinônimos, mas há diferenças epistemológicas importantes na sua utilização que devem ser esclarecidas. O último termo é o mais corrente entre os autores da promoção de saúde; no entanto, Monteiro (2010), psicóloga social da Venezuela, aponta a base da diferença entre esses dois termos na fonte do processo de adquirir controle e poder sobre os aspectos cruciais à vida das pessoas e das comunidades. No fortalecimento, a fonte de poder e controle é concebida sempre em função de buscas e de discussões coletivas, sendo que, na perspectiva do empowerment, ressalta-se a importância de instituições mediadoras que regulam as participações dos sujeitos e dos coletivos, o que não necessariamente significa postura ativa dos sujeitos diante dos temas prioritários. A própria inferência do significado do termo empowerment como delegar poder a outrem implica uma certa contradição e ambiguidade com uma construção coletiva, evidenciando maior coerência com o ideário da NPS o termo fortalecimento, que remete necessariamente a um processo, no qual "membros de uma 
comunidade desenvolvem, em conjunto, capacidades e recursos para controlar sua condição de vida (...), transformando, ao mesmo tempo, a si mesmos" (Monteiro, 2010, p. 72).

As ações que promovem saúde nessa perspectiva evidenciam-se como o resultado de um processo complexo que engloba o fortalecimento das capacidades dos indivíduos e das comunidades, buscando intervir no âmbito das ações do Estado e na singularidade e autonomia dos sujeitos. Essas ações transcendem as metodologias preventivas, pois deslocam o foco da doença para a perspectiva da saúde, como meta a ser concretizada por meio de instrumentos de intervenção na realidade (Santos et al., 2006). Os problemas de saúde demandam abordagens inovadoras e complexas, e os processos decisórios devem pautar-se nas subjetividades individuais e coletivas dos atores nos espaços do cotidiano, sendo que essa valorização do conhecimento popular e da participação social está na base da promoção de saúde nessa perspectiva (Czeresnia, 2009).

Vários autores ressaltam o fortalecimento e a participação comunitária como os conceitos-chave da NPS, conceitos esses que se encontram diretamente vinculados entre si (Carvalho, 2010; Czeresnia, 2009; Heidmann et al., 2006). A participação popular envolve mecanismos democráticos que propiciem o envolvimento das comunidades na eleição de prioridades, a tomada de decisões, a implementação e a avaliação das iniciativas. Esse processo de participação ativa da população tem como pressuposto a emancipação dos sujeitos e das comunidades, explicitando-se como um mecanismo propulsor do controle social. A participação ressaltada é um processo que inclui a população e os trabalhadores de saúde, pois a concretização de resultados positivos depende, em grande medida, da correlação de forças entre os interesses envolvidos e a implicação mútua (Freitas \& Mandú, 2010). As formas como a comunidade e os serviços de saúde se organizam revelam a utilização do fortalecimento como uma ferramenta agregadora, quando ambos, população e profissionais, se mostram membros do mesmo coletivo e portadores dos mesmos direitos (Carvalho, 2010).

A educação em saúde que compõe esse ideário é uma prática que busca embasar a conquista da autonomia pelos sujeitos e comunidades, não se restringindo apenas ao repasse de conhecimentos, mas buscando a construção de conhecimento aliado a melhores condições de vida por todos os que a integram. Isso não indica que a transmissão de conhecimentos não esteja incluída nessa proposta pedagógica, apenas é necessário ressaltar que ela não constitui seu objetivo maior (Besen et al., 2007). O sujeito é percebido em sua autonomia, em seu contexto cultural e político na busca de superação do instituído, rumo à produção de novos recursos e de modos de vida instituintes de saúde. A prática educativa insere-se como uma prática transformadora, que se constrói pautada no diálogo e no exercício da consciência crítica reflexiva, que prioriza a transformação da realidade e das pessoas envolvidas por meio da ampliação da capacidade de entender a complexidade dos determinantes do ser saudável (Buss, 2009).

A Política Nacional de Promoção em Saúde (Brasil, 2006) frisa a importância de priorizar a "produção de subjetividades mais ativas, críticas, envolvidas e solidárias" como condição para ampliar o comprometimento e a corresponsabilização entre profissionais de saúde e usuários. Essa ideia parte da compreensão que o estilo de pensamento da promoção em saúde prioriza a produção do conhecimento, das práticas e das políticas públicas por meio da construção e da gestão compartilhadas. 
"...educar,

higienizar, sanear estavam na ordem do dia.

(...) Eram ações indispensáveis à salvação nacional

oriundas do saber científico e portadoras de uma pedagogia civilizatória"

(Cardoso, 2003, p. 16).
No entanto, Freitas e Mandú (2010), ao analisar várias políticas públicas referentes à promoção de saúde, incluindo a PNPS, indicam contradições. Os autores afirmam que, se por um lado essa política assume uma postura que indica a defesa da equidade e do controle social na gestão das políticas públicas, por outro, enfatiza ações e estratégias individuais de caráter assistencial e de controle clínico epidemiológico dos riscos. Tal postura reflete um modelo de atenção baseado no ciclo doença-prevenção, mostrando-se incongruente com a noção de que a promoção da saúde coloca a saúde, e não a doença, na agenda das prioridades. Os autores concluem ressaltando que, apesar de as políticas serem coerentes com os princípios do SUS, fazem-se acompanhar de estratégias limitadas de intervenção, sem destaque para as práticas produtoras do acesso a bens e medidas que propiciem a qualidade de vida, a participação da população e o controle social.

A educação em saúde ocupa um lugar de destaque dentro desse contexto, sendo fundamental para a emancipação e o fortalecimento comunitário e para a participação popular. Mas, novamente, devemos atentar para as formas de conceber a educação em saúde, refletindo sobre as práticas desenvolvidas nessa área.

\section{As macrotendências em educação em saúde}

Segundo Da Ros (2000), no Brasil, há basicamente duas formas de se educar na área da saúde, dois estilos de pensamento distintos, desdobramentos das macrotendências na saúde em geral. Caracterizaremos primeiramente o estilo de pensamento da educação sanitária, termo adotado pelo autor, que objetiva a erradicação das doenças e que é importado por meio da influência da Universidade John Hopkins, nos EUA.
Essa instituição, onde se formaram dois fundadores da Faculdade de Saúde Pública da Universidade de São Paulo (USP), foi responsável pela disseminação inicial dessa forma de considerar a educação na área da saúde no território brasileiro. Podemos citar como uma de suas principais características a percepção de que as condições de saúde dependem basicamente do indivíduo, que deve receber as informações necessárias, sendo induzido a modificar seu comportamento a fim de evitar a entrada do agente causal da doença; sua visão da saúde é, portanto, ainda focada na doença e nas maneiras de evitá-la, e embasa-se em uma concepção biologicista, que concebe a educação na saúde como repasse de informações corretas à população. Apesar de mencionar a multicausalidade, seu foco está na percepção unicausal da doença e embasa-se em um modelo biomédico, no qual a figura do médico detém o poder.

Vários autores, como Da Ros (2004), Cardoso (2003) e Guareschi (1982), apontam a Fundação Rockfeller como um personagem principal da implantação do modelo sanitarista de assistência à saúde brasileiro, ligado ao ideário e aos interesses dos Estados Unidos e da grande indústria farmacêutica, que buscaram impulsionar em grande escala esse modelo, mascarado de um perfil modernizador para um país atrasado. Romper com o passado colonial era a mensagem evidente, portanto, “...educar, higienizar, sanear estavam na ordem do dia. (...) Eram ações indispensáveis à salvação nacional, oriundas do saber científico e portadoras de uma pedagogia civilizatória" (Cardoso, 2003, p. 16).

O Estado passou a ser o mediador desse progresso, imprimindo esse tipo de direcionamento às ações em saúde, sendo que boa parte dos profissionais da área passou a identificar-se com a política de saúde desenvolvida pelo Estado. Foi aberto um campo de consumo de 
inovações tecnológicas geradas em países mais desenvolvidos e consumidas sem questionamentos pelos países atrasados. Aos profissionais de saúde, que detêm o poder do conhecimento científico, foi delegada a função de guiar a população em suas ações passando as informações necessárias para torná-la mais saudável. Percebe-se, dentro dessa perspectiva, que o curso das doenças é alterado pela modificação dos hábitos e do estilo de vida individual, cabendo ao poder público e à educação sanitária os meios de internalizar esses comportamentos adequados na população. Esta, por sua vez, é considerada desprovida de conhecimento e de poder, devendo ser conduzida por aqueles que os detêm. Dessa forma, deslocase o eixo central da saúde pública das condições de vida daquela população para a responsabilização individual, isentando o Estado de sua responsabilidade de possibilitar condições mais saudáveis de vida para a população.

O outro estilo de pensamento, denominado por Da Ros (2000) educação em saúde, difere de forma bastante significativa do anterior, trazendo à tona a necessidade de contextualizar socio-historicamente o homem e destacando a determinação social do processo de saúde-doença. O foco recai em promover saúde, e não em evitar doenças, valorizando-se a atuação multiprofissional e interdisciplinar. A Escola Nacional de Saúde Pública da Fundação Oswaldo Cruz (FIOCRUZ) foi a instituição que disseminou inicialmente essa forma de pensar sobre a saúde no contexto brasileiro, influenciada pelo pensamento europeu. A educação em saúde nesse estilo de pensamento é prática que instiga a reflexão e põe em evidência a ação ideológica que permeia o modelo biomédico e a educação sanitária. Essa perspectiva da educação tem como referência principal o trabalho de Paulo Freire, buscando formar cidadãos críticos e transformadores da realidade.
O movimento da reforma sanitária, que, na sua origem, pactuava com esse novo estilo de pensamento, teve um papel importante na medida em que possibilitou uma revisão do conceito de saúde, trazendo ações que almejavam uma reorganização dos serviços e, concomitantemente, a revisão das práticas de educação em saúde. Esse movimento foi alavancado pelo processo de redemocratização do País, sendo que o recém-conquistado controle social possibilitou reivindicações, não mais de um sujeito passivo das ações do Estado, mas de agente ativo das transformações que deseja. Com a implantação do SUS, as políticas públicas passaram a caminhar no sentido de estabelecer diálogo com a sociedade organizada. Esse percurso é repleto de entraves e de resistências, advindas das contradições dos estilos de pensamento em saúde. Essa questão é ponto crucial para contextualizar quais valores embasam as práticas de saúde, configurando-se como delimitador de águas, apesar de a permanência das duas formas de considerar a educação em saúde coexistirem ainda hoje.

É necessário ainda esclarecer que há outros aprofundamentos possíveis na caracterização dos dois polos mais evidentes dentro do contexto de saúde, sendo que as práticas de promoção e de educação em saúde compõem nuances desses contrastes. Essas duas formas de fazer saúde, e seus mais variados nuances, fundamentam e estruturam as relações estabelecidas entre profissionais e usuários, repercutindo na organização dos serviços de saúde e nas relações estabelecidas entre profissionais de saúde e usuários.

Os reducionismos do modelo biomédico, que fragmentam em especialidades o ser humano, isolando-o de sua condição social concreta, abrem espaço para novas perspectivas críticas, que buscam suprir mais diretamente as necessidades e as demandas da população. Apesar disso, Da Ros (2004) afirma que as 
modificações ocorrem de forma mais lenta do que o desejado, ou seja, as práticas hegemônicas na área da saúde ainda persistem, dificultando o aparecimento de práticas mais condizentes com a proposta do SUS.

\section{Práticas hegemônicas em saúde: à guisa de conclusão}

Para a compreensão das práticas hegemônicas, é necessário delimitar o conceito de hegemonia, e, para tal feito, precisamos resgatar Gramsci (1984), pensador que realizou uma releitura ampliada da perspectiva marxista. Para esse autor, a classe dominante em uma sociedade não se impõe apenas pela força e pela coerção mas também pelo consenso, ou seja, pela cultura que conseguiu generalizar para outros segmentos sociais. Isso é a hegemonia, é um processo que expressa a consciência e os valores organizados na prática social por significados específicos e dominantes, sendo esse processo vivido de forma contraditória e difusa. Então, falar em práticas hegemônicas na área da saúde significa falar de práticas que reforçam a estrutura social dominante. Dessa forma, nas contradições presentes no cenário da saúde, o modelo biomédico, a promoção de saúde na perspectiva behaviorista e a educação sanitária são exemplos claros dessas práticas hegemônicas.

Sendo assim, podemos refletir sobre o fato de as macrotendências implicarem a articulação e o encadeamento de concepções, ideologias e proposição de ações nos vários níveis ou dimensões do fazer saúde, como se pode ver na figura abaixo:

\section{Macrotendências em saúde}

\section{Hegemônicas}

Modelo biomédico

Macrotendências em promoção de saúde

Promoção de saúde de características

behavioristas ou comportamentais

\section{Macrotendências em educação em saúde}

Educação sanitária

\section{Contra-hegemônicas}

Modelo da saúde coletiva

Nova promoção em saúde

Educação em saúde

Figura 1. Macrotendências em saúde

Levando-se em consideração o fato de que o SUS é uma proposta marcadamente contrahegemônica, as práticas ainda hegemônicas não condizem mais com o modelo de saúde proposto. Apesar disso, "profissionais de saúde partilham, sobretudo, o modelo biomédico hegemônico. É ele que dá hoje um consenso mínimo em torno da atenção à saúde, seja no plano coletivo ou individual" (Matos et al., 2005, p. 11).

Segundo Da Ros (2004), as práticas hegemônicas na saúde estão longe de ser abandonadas, pelo contrário, apesar de as leis que regem o Sistema Único de Saúde não ampararem tais práticas, estas seguem distorcendo na prática os conceitos avançados dessa proposta. A contra-hegemonia vive a confirmação de que transformar uma proposta em lei não é suficiente para colocá-la em prática.

A base das ações preconizadas pelo SUS são as práticas que visam à promoção da saúde e que constituem um dos pressupostos mais preciosos do nosso sistema de saúde. A busca da 
autonomia, conceito diretamente ligado à emancipação dos sujeitos, e a participação popular, que, segundo Sícoli e Nascimento (2003) são conceitos-chave da promoção em saúde, remetem-nos à importância de conscientização e de posicionamento ativo da população na busca de melhores condições de vida.

Dentro desse contexto, à promoção e à educação em saúde é dado um papel de destaque, no sentido de possibilitar a consciência do processo histórico que envolve o lugar dos coletivos na sociedade. Isso posto, cabe questionar qual o conceito de educação que embasa a prática diária dos profissionais do SUS: a que repassa informações corretas a serem assimiladas, dentro de um modelo claramente positivista, ou a educação transformadora que semeia a indagação permanente? E mais, qual o reflexo dessas ações na subjetividade dos usuários que utilizam os serviços de saúde e estabelecem relações verticais ou horizontais com esses profissionais?

Nesse sentido, mostram-se necessários não somente o entendimento da determinação social e a identificação e o enfrentamento dos macrovariantes, como, por exemplo, a elaboração de políticas públicas mais coerentes e democráticas, mas, sobretudo, a necessidade de evidenciar os meandros que permeiam as relações dos profissionais de saúde e dos gestores bem como dos usuários, imbricadas de valores e de sentidos que delimitam os espaços construídos pelos atores em seu componente histórico/relacional. Portanto, não se trata apenas de superar obstáculos da ordem do conhecimento, mas de construir discursos e práticas que estabeleçam uma nova relação com esses conhecimentos.

A sociedade contemporânea e suas características, aliadas às condições históricas da saúde no Brasil, impõem-nos a necessidade de apontar as contradições do cenário em discussão e de construir conhecimentos que abarquem novas possibilidades nesse contexto. Dessa forma, construir e partilhar conhecimento relativo às práticas de saúde que suscitem questionamentos de nossa postura, como profissionais da área, podem fornecer indícios e reflexões que se harmonizem com a busca de uma prática na saúde mais condizente com os pressupostos do SUS, que, ao discutir as contradições da realidade, possa fornecer subsídios para transformá-la. 


\section{Inea Giovana Silva-Arioli}

Mestre em Psicologia pela Universidade Federal de Santa Catarina (UFSC) e docente da Universidade do Planalto Catarinense (UNIPLAC), Lages - SC - Brasil.

E-mail: inea.giovana@gmail.com

\section{Daniela Ribeiro Schneider}

Pós-doutora pela Universidade de Valencia (Espanha) e docente da Universidade Federal de Santa Catarina (UFSC), Florianópolis - SC - Brasil.

E-mail: danischneiderpsi@uol.com.br

\section{Tatiane Muniz Barbosa}

Doutoranda em Saúde Coletiva pela Universidade Federal de Santa Catariana (UFSC) e docente da Universidade do Planalto Catarinense (UNIPLAC), Lages - SC - Brasil.

E-mail: tatibitati11@yahoo.com.br

\section{Marco Aurélio Da Ros}

Pós-doutor em Educação Médica e docente da Universidade do Vale do Itajaí (UNIVALI), Florianópolis - SC - Brasil. E-mail: ros@univali.br

\section{Endereço para envio de correspondência:}

Rua Modesto Casagrande, 537, Frei Rogério. CEP: 88508-060. Lages, SC.

Recebido 09/01/2012, 1aㅡ Reformulação 04/12/2012, Aprovado 11/04/2013. 


\section{Referências}

Besen, C. B., Souza Netto, M., Da Ros, M. A., Silva, F. W., Silva, C. G., \& Pires, M. F. (2007). A Estratégia Saúde da Família como objeto de educação em saúde. Saúde e Sociedade, 16(1), 57-68.

Brasil. Ministério da Saúde. (2002). As cartas da promoção em saúde. Brasília, DF: Ministério da Saúde.

Brasil, Ministério da Saúde. (2006). Política Nacional de Promoção da Saúde. (Série B. Textos Básicos de Saúde). Brasília, DF.
Buss, P. M. (2009). Uma introdução ao conceito de promoção da saúde. In D. Czeresnia \& C. M. Freitas (Orgs.), Promoção da saúde: conceitos, reflexões, tendências (2a ed.). Rio de Janeiro: Ed. Fiocruz.

Calatayud, F. M. (1999). Introducción a la psicologia de la salud. Buenos Aires: Ed. Paidós.

Campos, G. W. de S. (2010). Prefácio. In S. R. Carvalho. Saúde coletiva e promoção da saúde: sujeito e mudança (3a ed.). São Paulo: Hucitec. 
Cardoso, J. M. (2003). Comunicação e saúde: notas sobre a trajetória histórica e tendências atuais. In J. O. Silva \& R. Bordin. (Orgs.), Máquinas de sentido: processos comunicacionais em saúde. Porto Alegre: Dacasa Editora.

Carvalho, S. R. (2004). As contradições da promoção à saúde em relação à produção de sujeitos e a mudança social. Ciência \& Saúde Coletiva, 9(3), 669-678.

Carvalho, S. R. (2010). Saúde coletiva e promoção da saúde: sujeito e mudança (3a ed.). São Paulo: Hucitec.

Castiel, L. D. (2006). A noção de 'estilo de vida' em promoção de saúde: um exercício crítico de sensibilidade epistemológica. In M. Bagrichevsky, A. Palma, A. Estevão \& M. A. Da Ros. (Orgs.), A saúde em debate na educação física (pp. 45-66, Vol. 2). Blumenau, SC: Nova Letra.

Castiel, L. D., \& Diaz, C. A. (2007). A saúde persecutória. Rio de Janeiro: Ed Fiocruz.

Coelho, M. T. A. D., \& Almeida Filho, N. (2002). Conceitos de saúde em discursos contemporâneos de referência científica. História, Ciências, Saúde: Manguinhos, 9(2), 315-333.

Czeresnia, D. (2009). O conceito de saúde e a diferença entre prevenção e promoção. In D. Czeresnia \& C. M. Freitas (Orgs.), Promoção da saúde: conceitos, reflexões, tendências. Rio de Janeiro: Ed. Fiocruz.

Da Ros, M. A. (2000). Estilos de pensamento em saúde pública: um estudo da produção da FSP - USP e ENSP - FIOCRUZ, entre 1948 e 1994, a partir da epistemologia de Ludwick Fleck. (Tese Doutorado em Educação). Programa de PósGraduação em Educação, Universidade Federal de Santa Catarina, Florianópolis, SC.

Da Ros, M. A. (2004). A ideologia nos cursos de medicina. In J. J. N. Marins. Educação médica em transformação instrumentos para a construção de novas realidades. São Paulo: Editora Hucitec.

Delizoicov, D., Castilho, N., Cutolo, L. R. A., Da Ros, M. A. \& Lima, A. M. C. (2002). Sociogênese do conhecimento e pesquisa em ensino: contribuições a partir do referencial fleckiano. Cad. Bras. Ens. Fís., 52(19 Esp.), 52-69.

Fernandez, J. C. A., Andrade, E. A. de, Pelicioni, M. C. F., \& Pereira, I. M. T. B. (2008). Promoção da saúde: elemento instituinte? Saúde e Sociedade, 17(1), 153-164.

Figueira, T. R., Ferreira, E. F., Schall, V. T., \& Modena, C. M. (2009). Percepções e ações de mulheres em relação à prevenção e promoção da saúde na atenção básica. Rev. Saúde Pública, 43(6), 937-943.

Fleck, L. (2010). Gênese e desenvolvimento de um fato científico (Otto \& Camilo de Oliveira, trads.). Fabrefactum (Trabalho original em alemão, 1935).

Freitas, M. de L. de A., \& Mandú, E. N. T. (2010). Promoção da saúde na Estratégia Saúde da Família: análise de políticas de saúde brasileiras. Acta Paul. Enfermagem, 23(2), 200-205.

Gallo, P. R., \& Espírito Santo, S. K. A. M. (2009). A percepção de gestores de saúde sobre a rádio comunitária como instância mediadora para o exercício do controle social do SUS. Saúde em Debate, 33(82), 240-251.

Gaudenzi, P., \& Schramm, F. R. (2010). A transição paradigmática da saúde como um dever do cidadão: um olhar da bioética em saúde pública. Interface: Comunicação, Saúde, Educação, 14(33), 243-55.
Gramsci, A. (1984). Concepção dialética da história (5a. ed.). São Paulo: Civilização Brasileira.

Guareschi, P. A. (1982). Comunicação e poder: a presença e o papel dos meios de comunicação de massa estrangeiros na América Latina. Petrópolis, RJ: Vozes.

Heidmann, I. T. S. (2006). A promoção da saúde e a concepção dialógica de Freire: possibilidades de sua inserção e limites no processo de trabalho das equipes de Saúde da Família. (Tese de Doutorado). Universidade de São Paulo. Ribeirão Preto, SP.

Heidmann, I. T. S. B., Almeida, M. C. P., Boehs, A. E., Wosny, A. M., \& Monticelli, M. (2006). Promoção à saúde: trajetória histórica de suas concepções. Texto Contexto Enfermagem, 15(2), 352-358

Japiassu, H. F. (1992). Introdução ao pensamento epistemológico. Rio de Janeiro: F. Alves.

Lacerda, A. \& Valla, V. (2007). Homeopatia e Apoio Social: repensando as práticas de integralidade na atenção e no cuidado a saúde. In R. Pinheiro, \& R. Mattos (Orgs.),Construção da integralidade: cotidiano, saberes e práticas em saúde. Rio de Janeiro: UERJ/IMS/ ABRASCO.

Luz, M. T. (2007). É a promoção de saúde um novo paradigma? In M. T. Luz (Org.), Ordem social, instituições e políticas de saúde no Brasil: textos reunidos (pp. 217-224). Rio de Janeiro: CEPESC/IMS/ LAPPIS/ ABRASCO.

Matos, E., Gonçalves, J. R., \& Ramos, F. R. S. (2005). A epistemologia de Ludwick Fleck: subsídios para a prática interdisciplinar em saúde. Texto Contexto - Enferm. (online), 14(3), 383-390. doi: 10.1590/S0104-7072005000300009.

Monteiro, M. (2010) Teoría y práctica de la psicología comunitaria: la tensión entre comunidad y sociedad. (1a ed. 4a. Reimp.). Buenos Aires: Paidós.

Oliveira, M. R. (2008). A promoção da saúde na Estratégia Saúde da Família. (Dissertação de Mestrado). Escola Nacional de Saúde Pública, Rio de Janeiro.

Rabello, L. S. (2006). Promoção da saúde: desafio ou adaptação? A construção social do conceito, de Alma-Ata aos dias atuais, no Brasil e no Canadá. (Tese de Doutorado). Universidade de Brasília, Brasília, DF.

Sant'Anna, S. R., \& Hennington, E. A. (2010). Promoção da saúde e redução das vul-nerabilidades: estratégia de produção de saberes e (trans)formação do trabalho em saúde com base na ergologia. Interface: Comunicação, Saúde, Educação, 14(32), 207-15

Santos, L. M. dos, Oliveira, E. M. de, Crepaldi, M. A., \& Da Ros, M. A. (2010). Atuação dos coordenadores de grupos de saúde na rede docente assistencial. Revista Saúde Pública, 44(1), 177-84.

Sícoli, J. L., \& Nascimento, P. R. (2003). Promoção de saúde: concepções, princípios e operacionalização. Interface Comunicação, Saúde, Educação, 7(12), 91-112.

Verdi, M., \& Caponi, S. (2005). Reflexões sobre a promoção da saúde numa perspectiva bioética. Texto Contexto Enfermagem, 14(1), 2-8.

Woolf, S. H., Krist, A. H., Johnson, R. E., Wilson, D. B., Rothemich, S. F., Norman, G. J. et al. (2006). A practice-sponsored web site to help patients pursue healthy behaviors: An ACORN study. Ann. Fam. Med., 4(2), 148-52. 